\title{
Survival and Synapse Formation of Transplanted Rat Rods
}

\author{
P. Gouras, J. Du, M. Gelanze, R. Lopez, R. Kwun, \\ H. Kjeldbye, and W. Krebs \\ Department of Ophthalmology \\ Columbia University, New York, NY 10032, USA
}

\begin{abstract}
Isolated rods enzymatically removed from normal adult rat retina have been transplanted to the subretinal space of adult rats with a retinal dystrophy which has destroyed almost all the photoreceptors. These transplanted rods survive for months after transplantation during which time they form synapses with other retinal cells. Rod spherules with large amounts of synaptic vesicles and synaptic ribbons are found forming discreet contacts with pre- and postsynaptic densities in arrangements closely resembling those seen in the normal retina.
\end{abstract}

\section{KEY WORDS}

Transplanted rods, dystrophic rat retina

Reprint address:

P. Gouras

Dept. of Ophthalmology

Columbia University

630 West 168 Street

New York, NY 10032

USA

\section{INTRODUCTION}

Solitary photoreceptors $/ 11,14,18,19 /$ can be enzymatically isolated from the adult retina and maintained in vitro where they remain responsive to light /1/ and in the case of salamander rods /16/ form synapses with second-order retinal neurons. We have used this method to isolate solitary photoreceptors, predominantly rods, from normal pigmented adult rats and transplanted them to the subretinal space of 4- to 6-month-old albinotic rats with an inherited retinal dystrophy, which causes destruction of virtually all the photoreceptors at about 3 to 4 months of age $/ 2,5 /$.

In order to easily identify the transplant site we also dissociated pigmented retinal epithelial cells from normal rats and added them to the solution of photoreceptor cells just prior to surgery. These pigmented cells provide a marker for the transplant site because the dystrophic rat retina is albinotic and therefore the pigmented cells stand out within the small retinal area, about a millimeter in diameter, receiving the transplanted cells. The retinal dystrophy in this strain of rats is due to a genetic defect that prevents the retinal epithelium from phagocytozing the growing tips of the rods and this subsequently leads to 
their destruction $/ 6,10 /$. Therefore introducing normal retinal epithelial cells not only serves as a marker but may also facilitate the survival of the transplanted photoreceptors $/ 9,13 /$.

\section{MATERIALS AND METHODS}

\section{Isolation of Rods}

The methods we have used to isolate solitary mammalian photoreceptors resemble those of TownesAnderson et al. $/ 18,19 \%$. Adult rats were euthanized with intraperitoneal nembutal. The eyes were enucleated and the eye cup was submerged in Hank's solution saturated with $95 \% \mathrm{O}_{2} / 5 \% \mathrm{CO}_{2}$ at $\mathrm{pH}$ 7.4. The globes were hemisected at the ora serrata. The lens and vitreous were removed. The neural retina was then peeled away from retinal pigmented epithelium and placed in Hank's solution without $\mathrm{Mg}^{++}$and containing papain (5 units $/ \mathrm{ml}$, Worthington Biochemical, Freehold, NJ), cysteine $(2.7 \mathrm{mM})$ and $40 \mathrm{mM}$ glucose. The tissue was intermittently agitated for 10 minutes in a $95 \% \mathrm{O}_{2} / 5 \% \mathrm{CO}_{2}$ environment and then gently triturated with a wide base glass pipette releasing dissociated photoreceptors into the solution. The cell suspensions obtained were examined periodically by phase contrast microscopy to determine optimum dissociation and purity. In order to establish the purity of our solutions of transplanted photoreceptors we centrifuged and pelleted the dissociated material and examined it by electronmicroscopy. This revealed only rod photoreceptor organelles, including outer and inner segments, nuclei, all typical of rods together with rod axons and terminals. We found no evidence of other cells and no synapses contaminating these samples.

\section{Isolation of Pigmented Retinal Epithelial Cells}

The methods to dissociate retinal epithelial cells are similar to those we have used previously $/ 8,9 \%$. The pigmented retinal epithelial cells were obtained from the bisected normal rat eye by removing the neural retina and submerging the eye cup in Hank's solution, $\mathrm{Ca}^{++}$and $\mathrm{Mg}^{++}$free, and treated with $0.25 \%$ trypsin (GIBCO, Grand Island, NY) for $1 \mathrm{hr}$ at $37^{\circ} \mathrm{C}$. The trypsin solution is removed and replaced with minimum essential medium (MEM) solution. The retinal epithelial cells were pipetted off Bruch's membrane. An aliquot of the cell solution is used to determine the concentration and purity of the dissociated epithelial cells using a hemocytometer. The cell solution is centrifuged at 1000 RPM for 5 minutes and the supernatant removed in order to concentrate the cells.

\section{Transplantation of Dissociated Cells}

The cells are transplanted with a glass micropipette having a tip diameter of 120-130 microns as described previously $17,8,9,15 /$. This pipette is filled with a balanced salt solution and then a small air bubble to keep the transplant solution from being diluted into the larger volume of saline in the pipette. The pipette is then used to aspirate a small amount, about 5 microliters, of a solution of dissociated retinal pigmented epithelial cells, prepared earlier and subsequently a similar volume of solution containing the dissociated photoreceptors. The micropipette is then introduced into the subretinal space transchoroidally through a small incision in the sclera at the equator of the eye of an anesthetized four- to five-month-old dystrophic rat and the cell solution up to the air bubble in the micropipette injected into the subretinal space. One eye receives the transplanted cells; the other eye serves as a control. Because of its pigmentation, the transplant site can be examined immediately or at a later date by ophthalmoscopy through the dilated pupil.

\section{Histology}

The rats were euthanized with an overdose of nembutal at different times after transplantation surgery. The eyes were removed and incised at the limbus, placed in 3\% glutaraldehyde buffered Earle's solution and kept at $4^{\circ} \mathrm{C}$ for $24-48$ hours. Then they were washed in buffer and dissected with the aid of a surgical microscope in order to identify the transplant site by finding the intraretinal pigmentation produced by the co-transplanted retinal epithelium. This area was cut out, dehydrated, embedded in epoxy resin and sectioned for examination by light and electronmicroscopy. A similar section from the control eye was processed in parallel. We have examined 41 eyes which 
received transplanted rods: 33 within 1-2 weeks and 8 within 1-2 months after transplantation surgery. In earlier experiments both eyes were used for transplantation; in later ones the contralateral eye served as a control. In the former, our control was an adjacent area of retina which had not received any transplanted cells. Each block was sectioned serially until the pigmented epithelial cells were found by light microscopy, usually together with a group of rod cell nuclei (see Fig. 2). At this point ultra thin sections were taken and examined by electronmicroscopy. Electronmicrographic photomontages were made of the area and examined for rod organelles: outer and inner segments, nuclei and synaptic terminals and vesicles, synaptic ribbons and contacts. These were compared with similar montages from the control retinas.

The rats used in these experiments are from a congenic Royal College of Surgeons strain of rats, tanhooded pink eyed, homozygous $(p / p)$ for the pink eye dilution gene as recipients and pigmented $(\mathrm{p} /+)$ rats as donors, obtained through the courtesy of M. LaVail.

\section{RESULTS}

Figure 1 illustrates by light microscopy normal (A) compared to four-month-old dystrophic (B) retina. In the dystrophic retina the entire photoreceptor layer has disappeared leaving the neural retina at about half the thickness of the normal retina. This is most obvious from the absence of the darkly staining photoreceptor nuclei, about 7 to 10 layers thick, as well as the loss of inner and outer segment organelles and the external plexiform layer where the photoreceptors synapse with other retinal neurons. In the dystrophic retina all of these structures are lost.

Figure 2 shows transplant sites at one (A) and two (B) weeks and at one (C) and two (D) months after transplantation surgery. In all cases the rod cell nuclei found in these areas marked by the transplanted pigmented epithelial cells are much more numerous than anything we can find elsewhere in this retina or in the contralateral control eye (Fig. 1B). In some experiments (Fig. 2A) there are as many as three rows of rod cell nuclei in the same place where the pigmented epithelial cells are located. Elsewhere in the retina, these nuclei and pigmented cells were absent.
The relatively thin neural retina invariably reattaches to the underlying epithelial layer. Sometimes some of the host retinal epithelial cells are dislodged by the stream of the transplantation solution and pigmented donor epithelial cells insert themselves in this layer (Fig. 2C and D). There is little indication of outer segment material at the light microscopic level within the retina. There is also no evidence of inflammation or rejection of the transplant material.

Electronmicroscopy of the transplant site shows typical rod cell nuclei with some outer segment material (Fig. 3). The cytoplasm of these cells appears healthy, in Figures 3 and 4 at one month after transplantation. Rod cell nuclei, if any, cannot be found in these numbers in the control retinas. The melanin granules within the retinal pigmented epithelial cell, the cytoplasm of which is visible in the upper left corner of Figure 4 (arrow), are unequivocal evidence that this is the transplant site.

Outer segments are relatively rare in the transplant sites especially at one to two months after transplantation surgery. The best example we have found is shown in Figure 5. This shows a relatively short outer segment connected to its ciliary stalk and rootlet in a seven-month-old dystrophic rat. Interestingly, a melanin granule identifies the cytoplasm of a transplanted retinal pigment epithelial which abuts the outer segment. This close association of a retinal epithelial cell to the transplanted outer segment could be responsible for its longer survival than those of other transplanted rods. Outer segment material has never before been seen by us or reported by others in dystrophic rats of this age $/ 12 /$.

The most striking characteristic of the transplant site, especially at one or two months after surgery, is the abundance of synaptic structures, i.e., vesicles, synaptic ribbons and pre- and postsynaptic densities present. Figure 6 illustrates examples of such synapses cut in both radial and tangential directions through rod spherules in a six-and-a-half month-old dystrophic rat retina, two months after photoreceptor transplantation. The postsynaptic structures do not have the cytoplasmic characteristics of either photoreceptor or pigmented retinal epithelial cells, having a relatively clear cytoplasm with either a few or no vesicles.

Measurements of the number of ribbon synapses that could be identified in electronmicrographic photomontages at different times after transplantation 


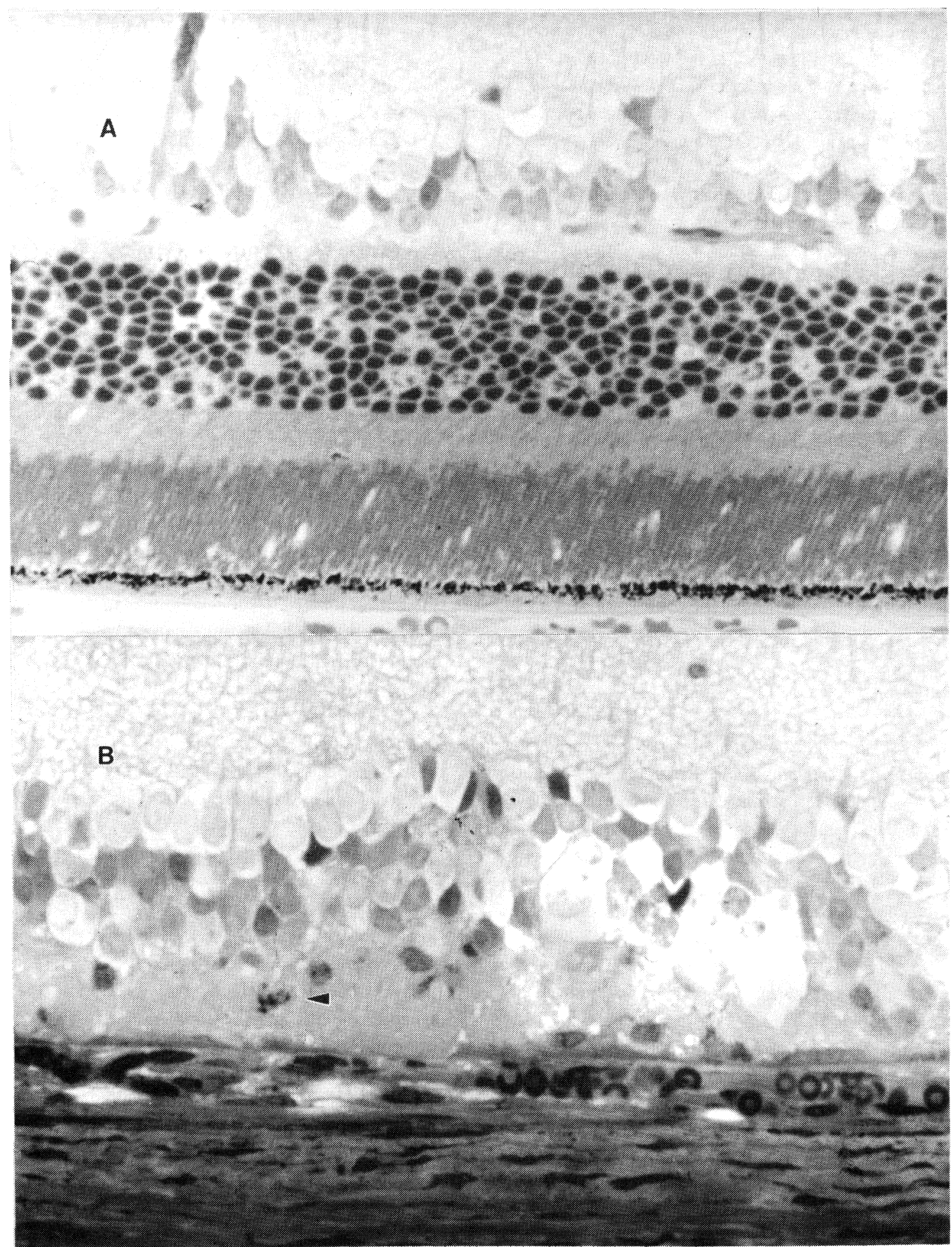

Fig. 1: Light micrographs showing the normal adult rat retina $(A)$ and the 4-month-old dystrophic rat retina (B). The latter is distınguisnea by the total absence of the photoreceptors including about 7-10 rows of darkly staining nuclei and the inner and outer segments of the photoreceptors. The dystrophic retina is about half the thickness of the normal retina. A macrophage (1B, arrow-head) can occasionally be seen in the area of the external plexiform layer. 


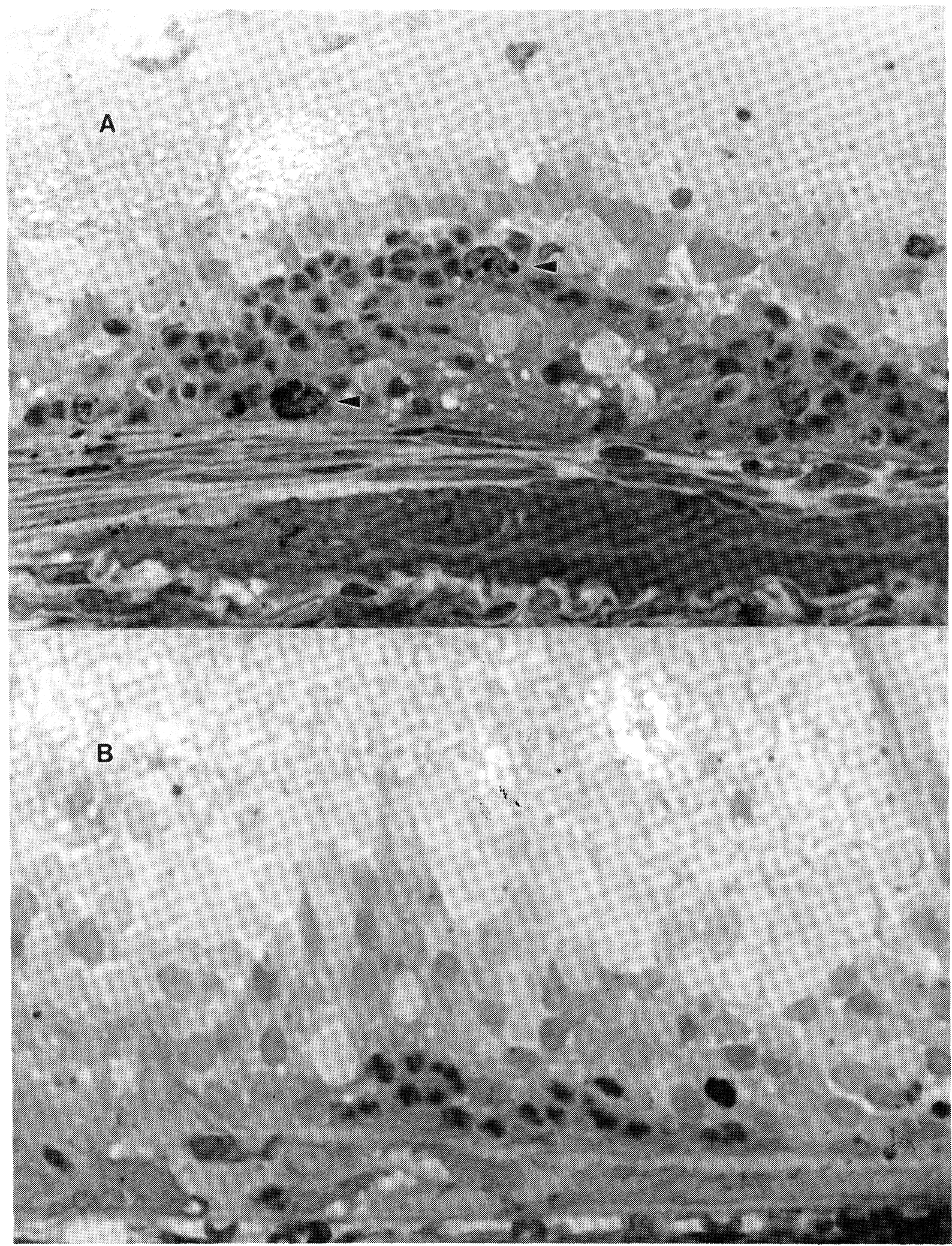

Fig. 2: Light micrographs show transplantation sites in rats at 1 week (A), 2 weeks (B), 1 month (C) and 2 months (D) after transplantation surgery. Trans-planted rod cell nuclei with darkly stained chromatin (arrowheads, D) are apparent. Pigmented retinal epithelium co-transplanted with the rods and used as a marker of the transplant site are also seen (arrowheads, $\mathrm{A}$ and $\mathrm{C}$ ). These retinas are to be compared with the control dystrophic retina (Fig. 1B). 


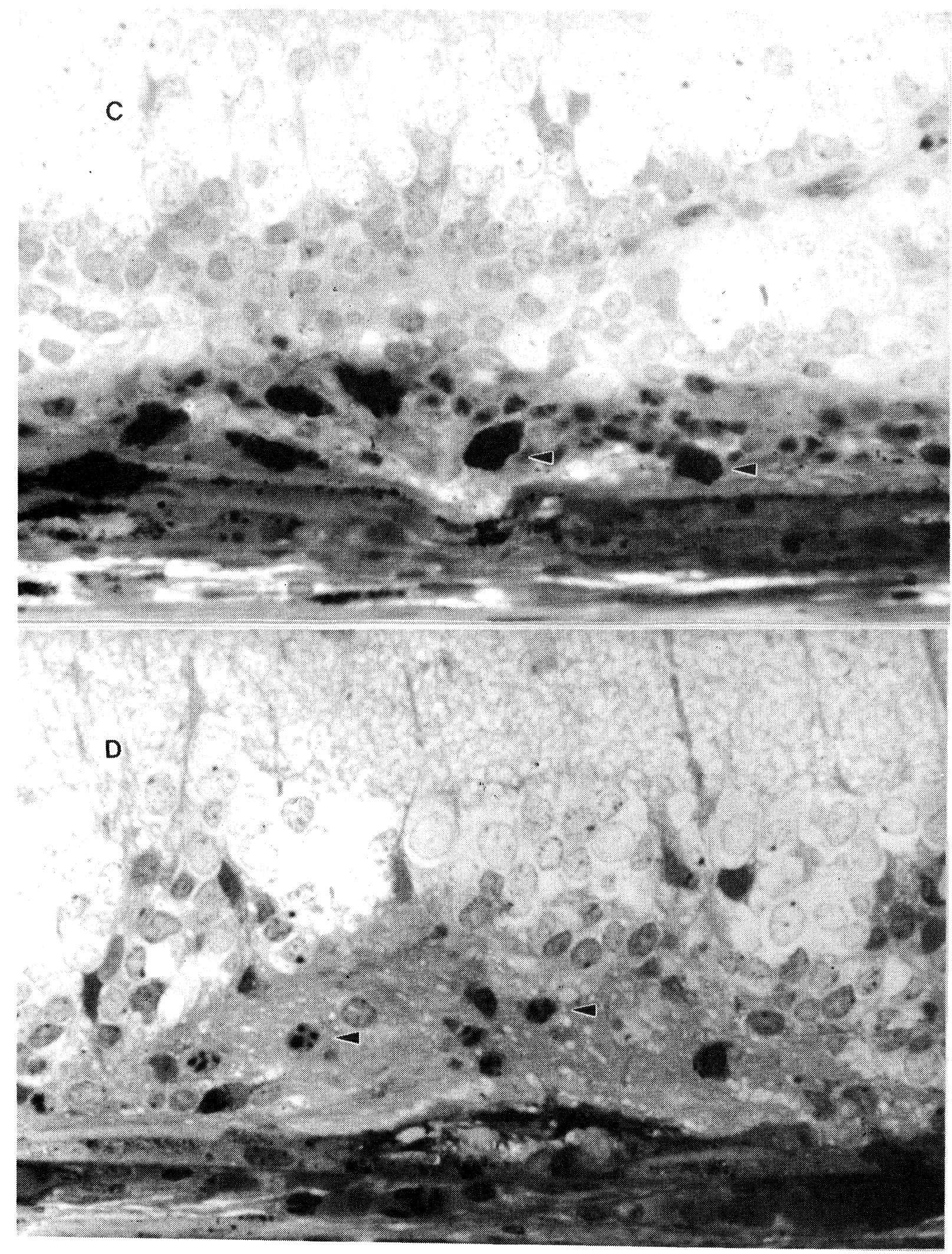

Fig. 2 (cont.) 


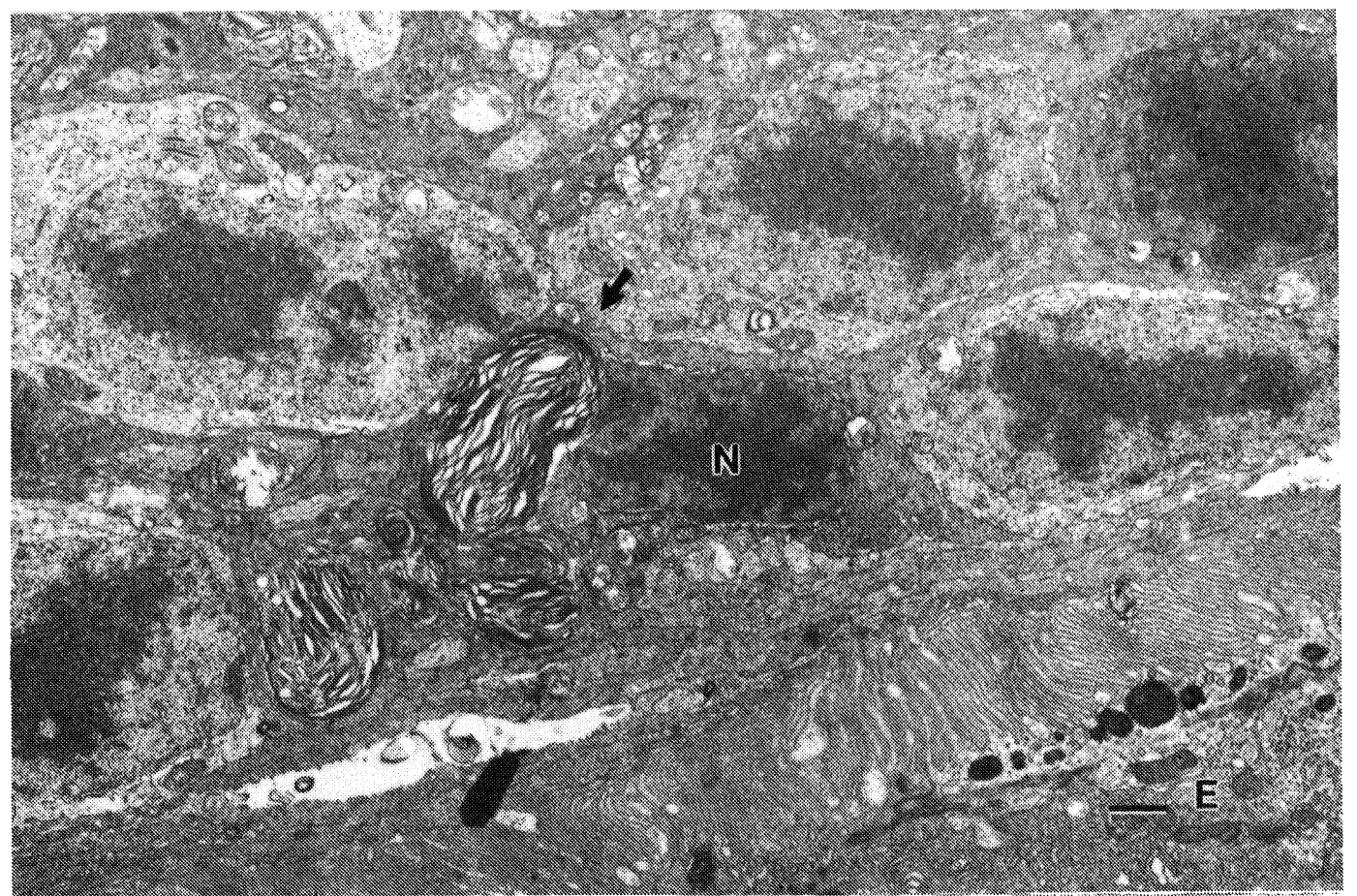

Fig. 3: Electronmicrograph showing a transplant site at 1 month after surgery. The characteristic clumpea cnromatin pattern of the rod cell nuclei $(N)$ is revealed together with adjacent outer segment material (arrow). The scale bar indicates one micron.

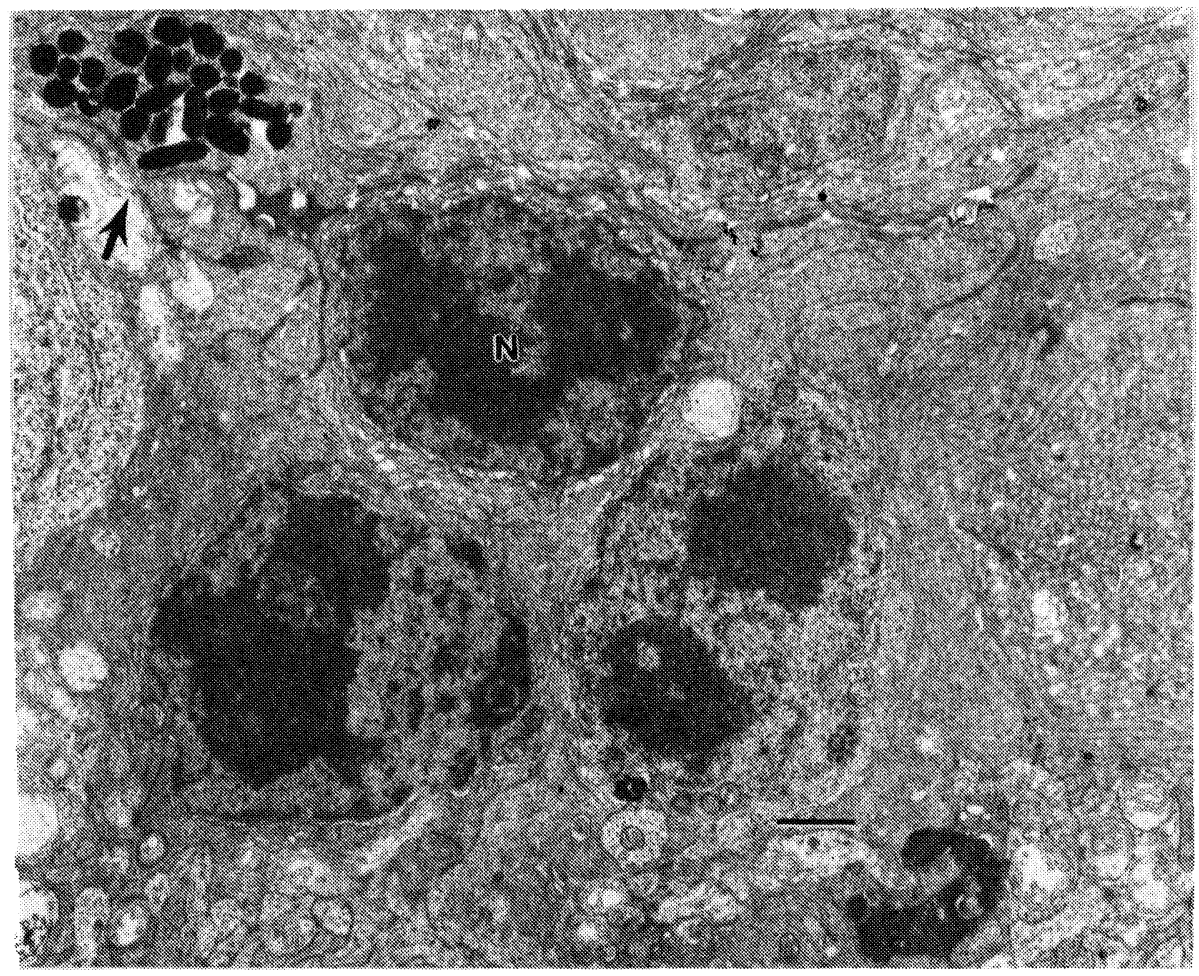

Fig. 4: Electronmicrograph showing a transplant site at 1 month after surgery. The melanin granules within the cytoplasm of a transplanted pigmented retinal epithelial cell (arrow) marks this as the transplant site. A rod nucleus is labeled (N). The scale bar indicates one micron. 


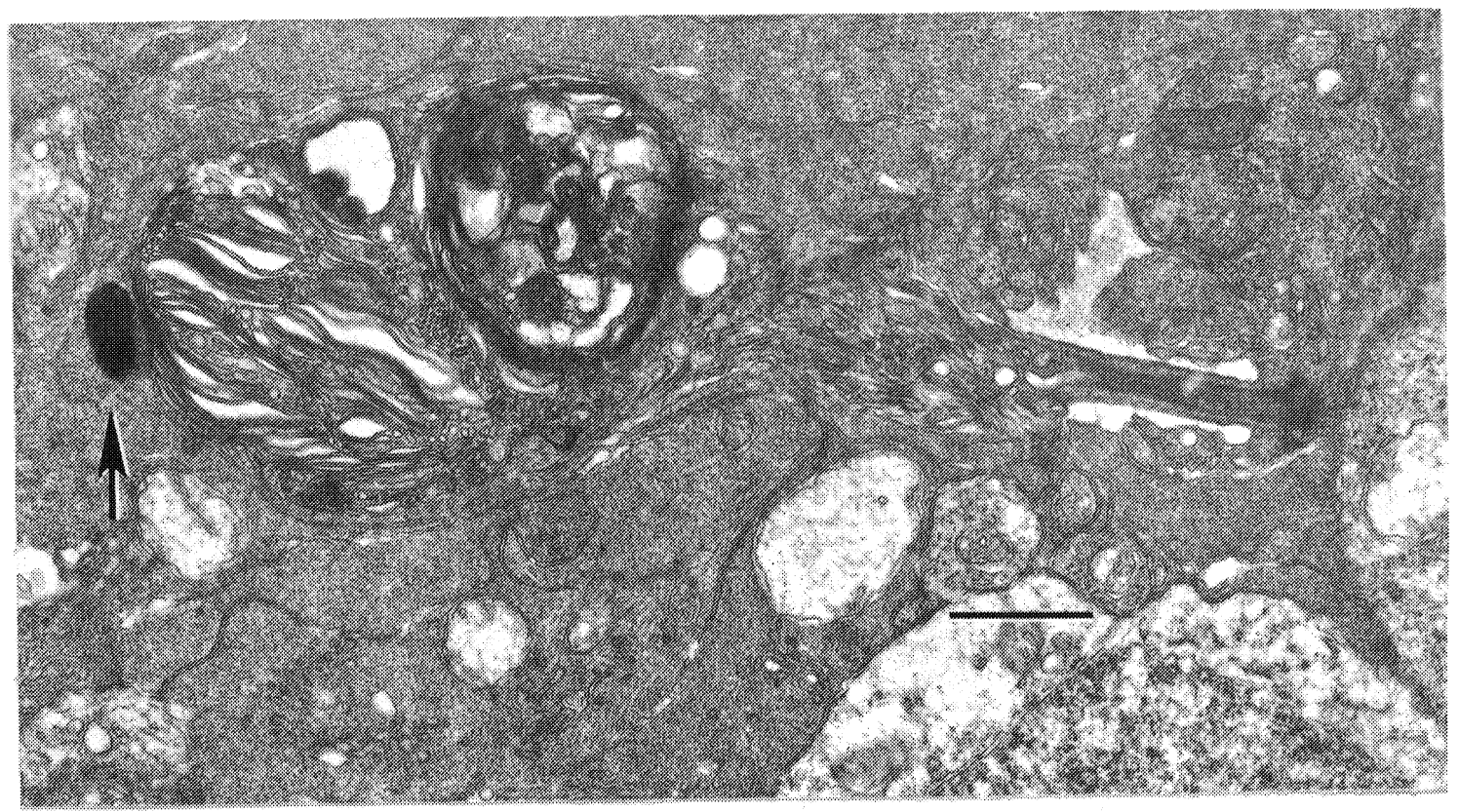

Fig. 5: Electronmicrograph showing an outer segment connected to its cilial stalk and basal body in a transplant site, marked by th melanin granule (arrow) in the cytoplasm of a transplanted pigmented retinal epithelial cell. The scale bar indicates one micror
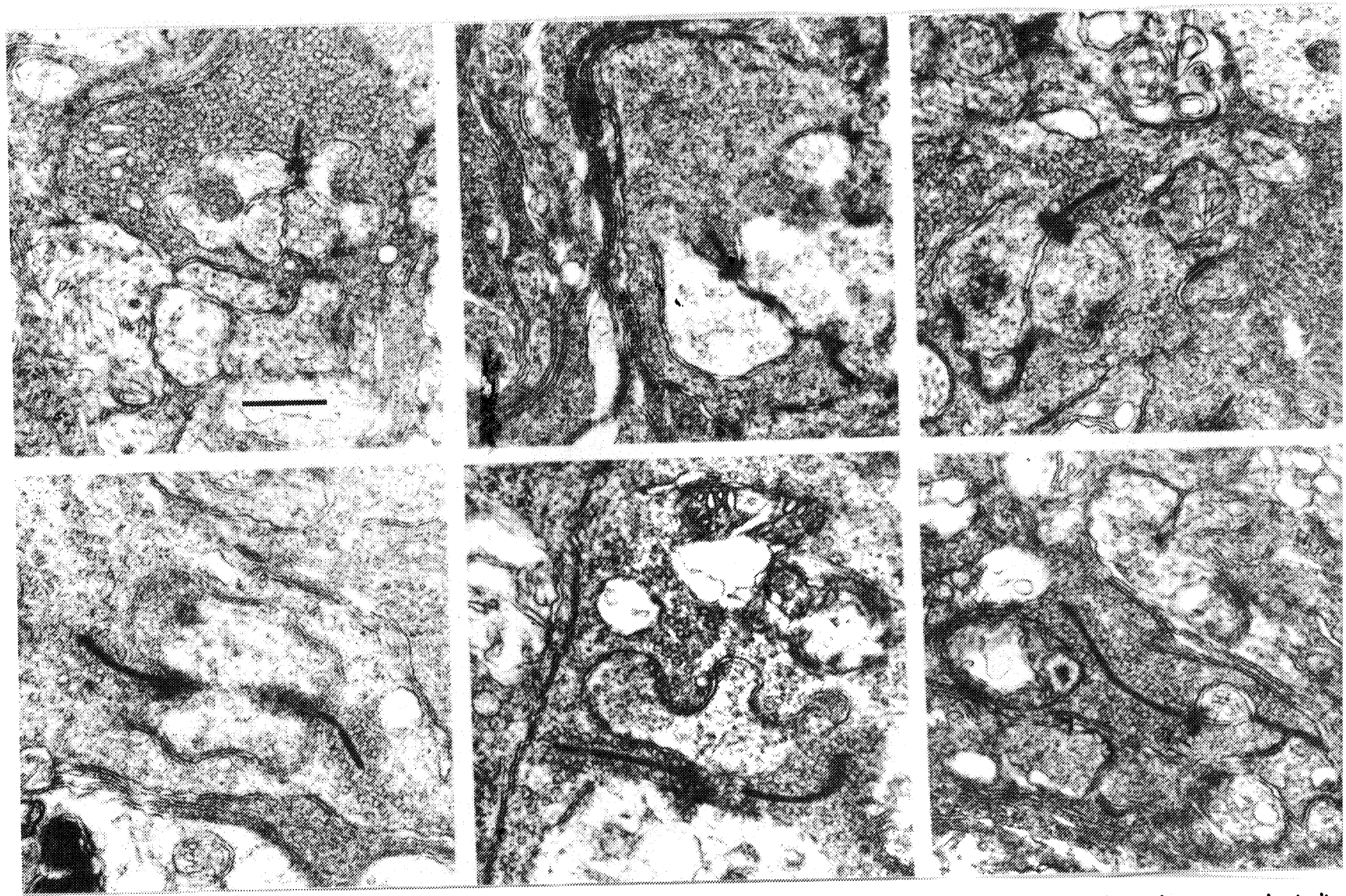

Fig. 6. Electronmicrographs of synaptic structures found within what corresponds to the external plexiform layer in a transplant site 2 months after trans-plantation when the dystrophic rat is $61 / 2$ months old. There are many rod spherules present, all of whi are filled with synaptic vesicles together with ribbons; many synaptic contacts are evident by both pre- and postmembra densities. The scale bar indicates 0.5 micron. 
show an increase from $3 / 1000 \mu \mathrm{m}^{2}$ at $1-2$ weeks to $19 / 1000 \mu \mathrm{m}^{2}$ at 1-2 months after transplantation. We could find no synapses within the outer plexiform layer of the control retinas. On the other hand, the number of outer segments we observed decreased progressively with time after transplantation.

\section{DISCUSSION}

The results indicate that dissociated rods from adult rats can survive in the subretinal space of the dystrophic rat retina for at least two months. The evidence that they are transplanted cells is the following: (1) They have been transplanted into the dystrophic retina of rats 4-6 months of age at a time when all of the photoreceptor cells have disappeared. This eliminated the possibility that the procedure itself prevented the degeneration of host photoreceptor cells. (2) Within the relatively small area receiving the transplanted cells, marked by the presence of cotransplanted pigmented retinal epithelium, relatively large numbers of rod cell nuclei were found. Other regions of the retina or the contralateral retina, receiving no transplanted cells, contained none of these nuclei. (3) Electronmicroscopy confirmed the characteristic clumped chromatin pattern of the rod cell nuclei together with outer segment material. Relatively intact rod outer segments connected to an inner segment were found in dystrophic retinas of rats 6-7 months of age, long after all other outer segments have disappeared from the control retinas. (4) Numerous rod spherules, containing a large number of vesicles and ribbons, making normal synaptic contacts with other retinal cells fill the transplant site. These synapses increase considerably with time after transplantation. We were unable to find synapses in the outer plexiform layer of the control retinas. LaVail et al. /12/ have found rod synapses in an adult dystrophic rat retina, but they do not appear to be as abundant as what we have found within the transplant zone. We have recently obtained evidence from radioautography of tissues containing transplanted photoreceptors, previously labeled with tritiated thymidine administered to newborn donor rats, that photoreceptors survive for at least one month after transplantation (unpublished results).

There is other evidence that transplanted rods can survive and form synapses in host retina. Silverman and Hughes /17/ have reported that retinal slices containing photoreceptors will survive and del Cerro et al. $/ 3,4 /$ have reported that a mixture of dissociated embryonic retinal cells, including photoreceptors, will form synapses in host rat retina. In the latter work the mixture of different retinal cells in their inoculum prevented them from determining whether the postsynaptic targets are host or donor elements. Our use of pure populations of dissociated rods indicates that the postsynaptic targets must be host retinal cells. The possibility that the postsynaptic structures were either the donor epithelial cells or the rods was unlikely because of the cytoplasmic characteristics of the postsynaptic cells. It will be important to further confirm this with the use of electronmicroscopic markers for either or both the donor and the host cells.

These results are an evolution of earlier research demonstrating that photoreceptors, isolated from the retina, remain functional $/ 11,18,19 /$ and even form synapses $/ 16 /$ in vitro. The formation of synapses on host neurons is crucial to advancing the use of this method to examine retinal cell biology as well as possibly correcting those retinal degenerations which uniquely destroy photoreceptors but leave the rest of the retinal machinery for vision relatively intact.

Another crucial factor for making this technique potentially therapeutic is the maintenance of normal outer segments. We found that outer segments decreased in number with time after transplantation. This may be due in part to the poor alignment of these organelles with the retinal epithelium which is a drawback of using dissociated cells. The retinal epithelium in the dystrophic retina is itself defective and this may add to the problem in the particular animal model we have used. Our choice of this model was because it contains a retina in which the photoreceptor cells have disappeared. Therefore, identifying the transplanted rod cells was enormously facilitated.

The use of solutions of dissociated retinal epithelial 17/ or neuroretinal /20/ cells has advantages in transplantation. Rather than using segments or slices of organized tissue, solutions of cells can be used and injected with micropipettes or cannulas. This minifies the surgical instrumentation and reduces the trauma required to reach a target in the central nervous system. It also facilitates microscopic examination of an aliquot from the cell suspension prior to trans- 
plantation, which can provide insights into the viability and purity of the inoculum.

The use of single cell types, as done in this study, seems particularly attractive to neuro-transplantation because in the nervous system it is the number and organization of specific cell types that determine function. The photoreceptor is a particularly specialized neuron which is frequently selectively damaged by genetic defects and/or toxic factors. There are a number of retinal degenerations where destruction of this cell system alone prevents the remainder of the visual system from functioning. Under these circumstances photoreceptor transplantation could become a feasible treatment.

\section{ACKNOWLEDGEMENT}

This work was supported by NIH Grant EY03854, The Harold G. and Leila Y. Mathers Charitable Foundation, the Bedminster Fund, Inc., Howard Hughes Medical Institute, and Research to Prevent Blindness, Inc.

\section{REFERENCES}

1. Bader CR, MacLeish PR, Schwartz EA. A voltage clamp study of the light response in solitary rods in the tiger salamander. J Physiol (Lond) 1979; 296:1-26.

2. Bourne JE, Campbell DA, Tansley K. Hereditary degeneration in the rat retina. $\mathrm{Br} \mathrm{J}$ Ophthalmol 1938; 22:613-623.

3. del Cerro M, Notter MFD, Wiegand SJ, Quijiang L, del Cerro C. Intraretinal transplantation of fluorescently labeled retinal cell suspensions. Neurosci Lett 1988; 92:21-26.

4. del Cerro M, Notter MFD, del Cello C, Wiegand SJ, Grover DA, Lazar E. Intraretinal transplantation for rod-cell replacement in light-damaged retina. J Neur Transplant 1989; 1:1-10.

5. Dowling JE, Sidman RL. Inherited retinal dystrophy in the rat. J Cell Biol 1962; 14:73-109.

6. Edwards RB, Szamier RB. Defective phagocytosis of isolated rod outer segments by RCS rat retinal pigment epithelium in culture. Science 1977; 197:1001-1003.
7. Gouras P, Flood MT, Kjeldbye H. Transplantation of cultured human retinal cells to monkey retina. Am Acad Brasil Cienc 1984; 56:431-443.

8. Gouras P, Lopez R, Brittis M, Kjeldbye HM, Fasano MK. Transplantation of retinal epithelium. In $E$ Agardh, B Ehinger (Eds.), Retinal signal systems, degenerations and transplants. Amsterdam: Elsevier, 1986, pp. 271-286

9. Gouras P, Lopez R, Kjeldbye H, Sullivan B, Brittis M. Transplantation of retinal epithelium prevents photoreceptor degeneration in the RCS rat. In MM LaVail, RE Anderson, JG Hollyfield (Eds.), Inherited and environmentally induced retinal degenerations. New York: Alan R Liss, 1989, pp. 659-671.

10. Herron WL, Riegel BW, Myers OE, Rubin ML. Retinal dystrophy in the rat-a pigment epithelial disease. Invest Ophthalmol 1969; 8:595-604.

11. Lam DMK. Biosynthesis of acetylcholine in turtle photoreceptors. Proc Natl Acad Sci USA 1972; 69:19871991.

12. LaVail MM, Sidman M, Rausin R, Sidman RL. Discrimination of light intensity by rats with inherited retinal degeneration. Vis Res 1974; 14:693-702.

13. Li L, Turner JE. Inherited retinal dystrophy in the RCS rat. Photoreceptor rescue by RPE cell transplantation. Exp Eye Res 1988; 47:911-917.

14. Lolley RH, Lee RH, Chase DG, Racz E. Photoreceptor cells dissociated from mature mice retinas. Invest Ophthalmol Vis Sci 1986; 27: 285295.

15. Lopez R, Gouras P, Brittis M, Kjeldbye H. Transplantation of cultured rabbit retinal epithelium to rabbit retina using a closed eye method. Invest Ophthalmol Vis Sci 1987; 28:1131-1137.

16. MacLeish $P$, Townes-Anderson $E$. Growth and synapse formation among major classes of adult salamander retinal neurons in vitro. Neuron 1988; 1:751-760.

17. Silverman MS, Hughes SE. Transplantation of photoreceptors to light damaged retina. Invest Ophthalmol Vis Sci 1989; 30:1684-1690.

18. Townes-Anderson E, MacLeish PR, Raviola E. Rod cells dissociated from mature salamander retina: Ultrastructure and uptake of horseradish peroxidase. J Cell Biol 1985; 100:175-188.

19. Townes-Anderson E, Dacheux RF, Raviola E. Rod receptors dissociated from the adult rabbit retina. J Neurosci 1988; 8:320-331.

20. Zucker M, Seiler M, Aramant R, Adolph AR. Neurocircuitry of retinal transplants: ultrastructural observations. Neurosci Abst 1989; 15:367. 

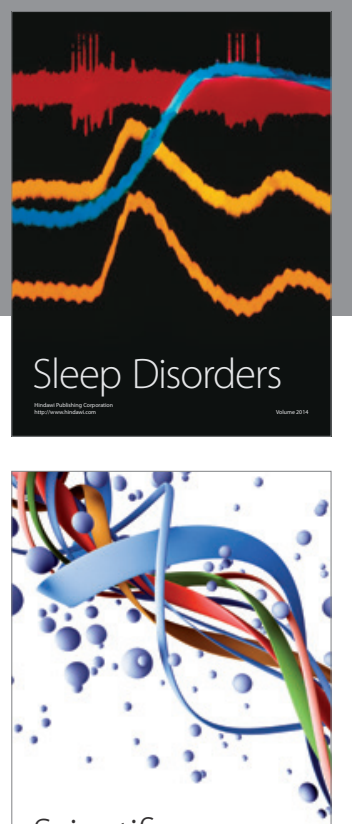

Scientifica
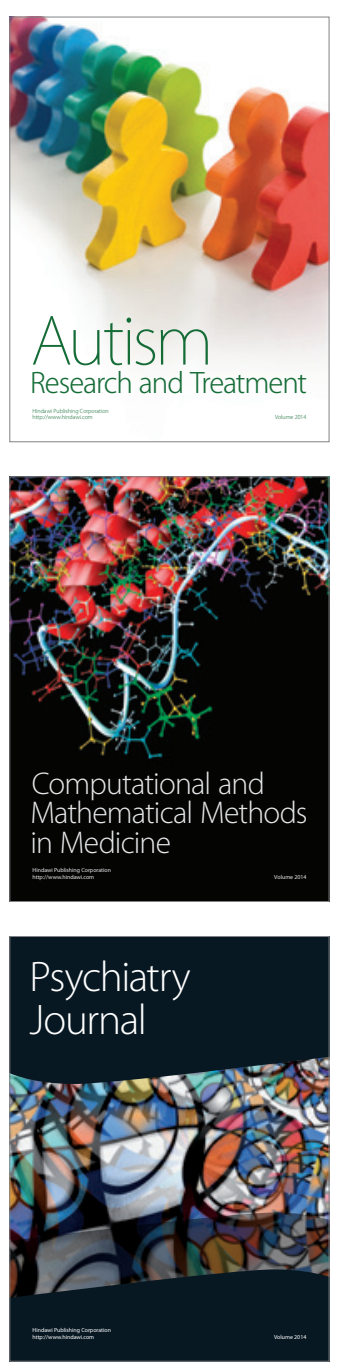
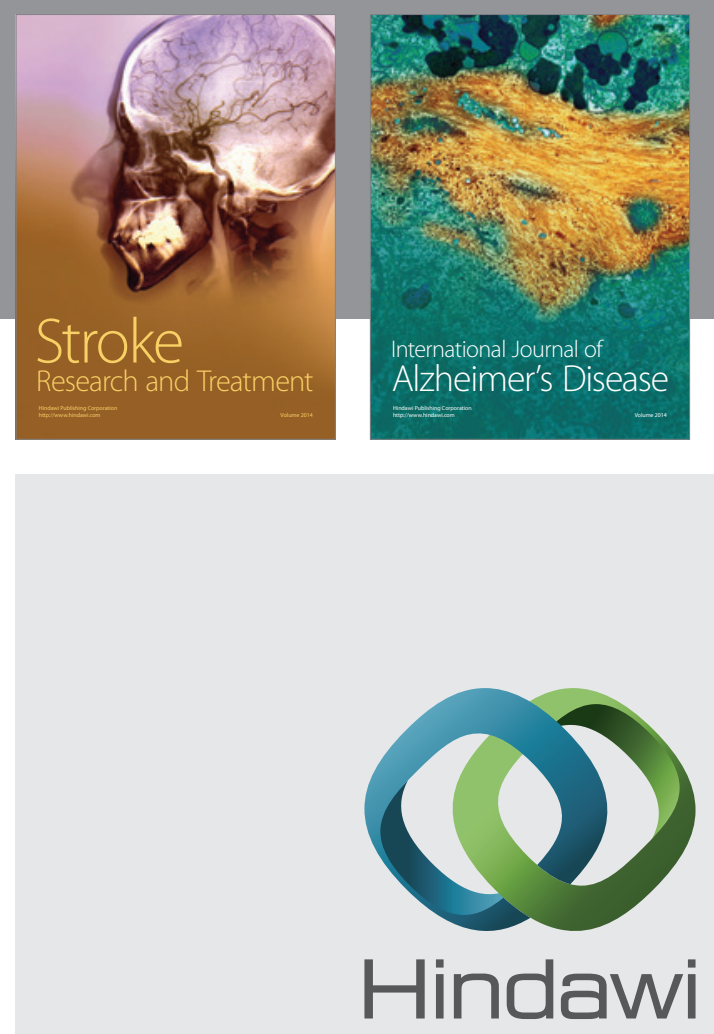

Submit your manuscripts at

http://www.hindawi.com
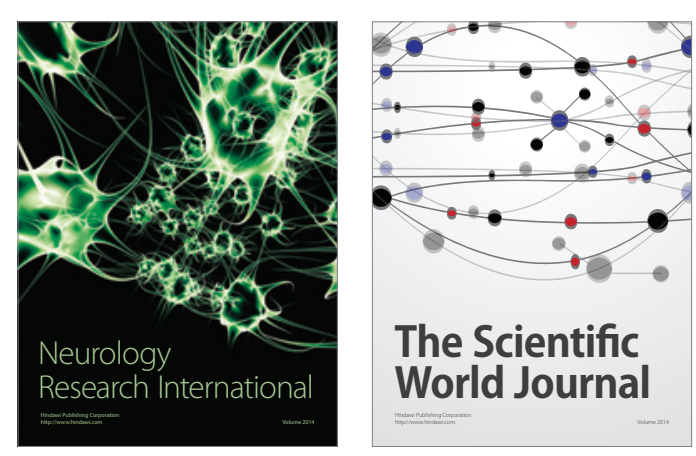

The Scientific World Journal

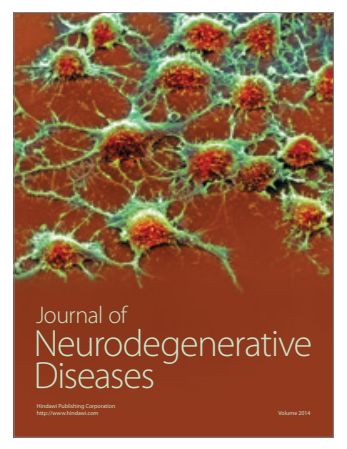

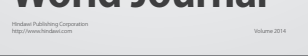

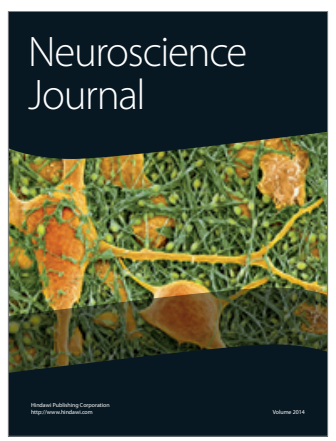

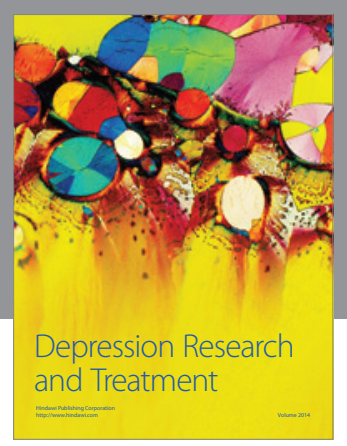
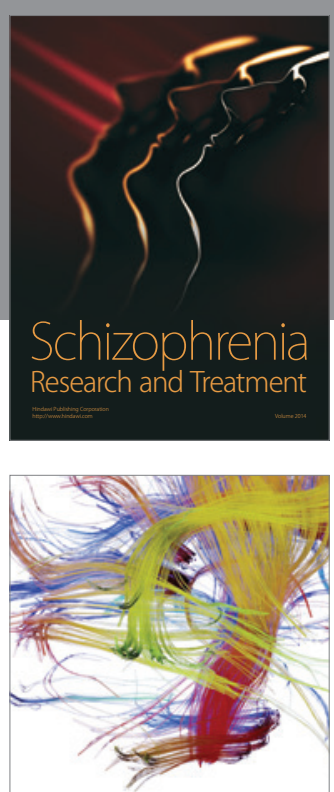

Brain Science

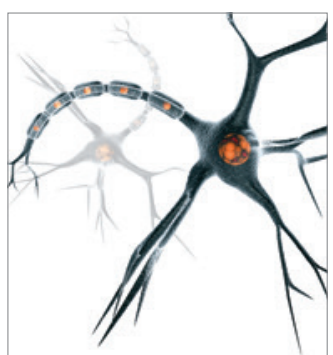

Neural Plasticity
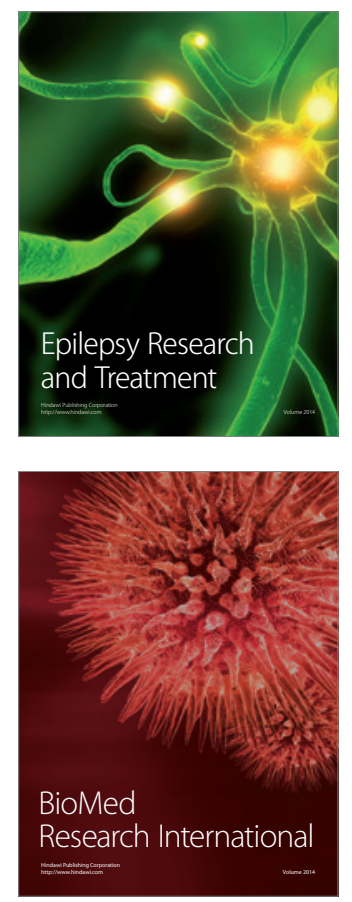

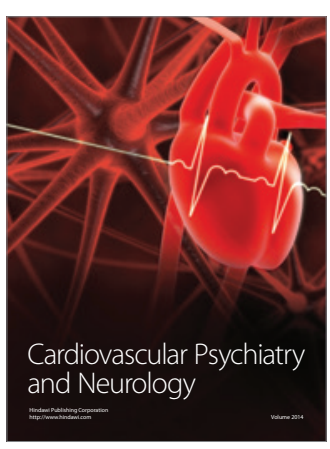

Parkinson's

Disease
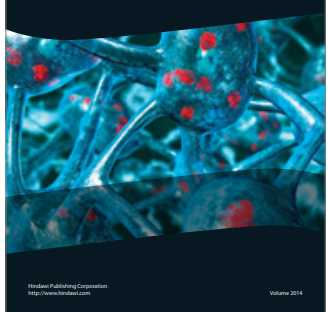